\title{
The effects of sample storage on polymerase chain reaction-based detection of Toxoplasma gondii in amniotic fluids
}

\author{
A. W. L. JOSS and D. O. HO-YEN \\ Scottish Toxoplasma Reference Laboratory, Raigmore Hospital NHS Trust, Inverness $1 \mathrm{~V} 2$ 3UJ
}

\begin{abstract}
The effects of sample storage, target preparation and annealing temperature on a nested polymerase chain reaction (PCR) test for Toxoplasma gondii DNA were investigated with experimentally seeded amniotic fluids to simulate congenital infection. Aliquots of 17 amniotic fluid samples remaining after investigation for conditions other than toxoplasmosis and seeded to contain small numbers of $T$. gondii tachyzoites, were tested after storage for up to 2 weeks. There was no deterioration in test sensitivity on samples stored for 1-2 weeks at room temperature; thus, samples sent by post to reference laboratories are acceptable for examination. There was no significant difference in the results from two target preparation methods or two different annealing temperatures. One-to-ten parasites were detectable in 13 of 17 test samples. The significant feature in the remaining four samples was the use of washed stored parasites to seed the amniotic fluids rather than any feature of the amniotic fluids used or the test. False positive results were found in up to $15 \%$ of unseeded amniotic fluid samples, which contrasts with only $1.9 \%$ for the same PCR test in other routine or negative control samples tested as part of the laboratory's reference diagnostic work. The difference illustrates the increased risk of cross-contamination in PCR when the majority of specimens tested are positive. The results suggest that PCR techniques are likely to be sensitive and effective tools for the routine diagnosis of congenital toxoplasma infection.
\end{abstract}

\section{Introduction}

Congenital toxoplasmosis affects about one in 1000 babies in the UK of whom $8 \%$ may suffer immediately evident serious ocular or brain damage and even asymptomatic babies will probably suffer some form of ocular impairment later in life [1]. Antenatal diagnosis of congenital toxoplasmosis currently relies on evidence from several laboratory techniques, none of which is entirely satisfactory. Proof of fetal infection following maternal infection during pregnancy usually requires sampling of fetal blood, by cordocentesis, as well as amniotic fluid [1]. These samples are subject to tissue culture and animal culture, serological tests and haematological and biochemical analysis for nonspecific abnormalities $[2,3]$. As none of these tests is $100 \%$ sensitive, all are essential to confirm fetal infection, and even then up to $10 \%$ of congenital infections may not be detected [4]. The most sensitive test, parasite culture in mice, requires $4-6$ weeks to

Received 6 Feb. 1996; revised version received 1 July 1996; accepted 3 July 1996.

Corresponding author: $\mathrm{Mr}$ A. W. L. Joss. produce a result. Furthermore, cordocentesis involves a risk of miscarriage and is only undertaken in specialist centres [5].

A recent study [6] achieved greater success than previous methods at isolating toxoplasma from amniotic fluids by mouse inoculation but still required fetal blood tests, including specific IgA as well as IgM tests, to achieve maximum detection of fetal infection. Therefore, the description of a very sensitive and reliable polymerase chain reaction (PCR) technique for Toxoplasma gondii performed only on amniotic fluid samples to diagnose fetal infection [7] was a major step forward. This PCR was used in a laboratory with a regular daily demand for diagnosis of fetal infection and was designed to minimise the risk of false positive results due to cross-contamination from sources of $T$. gondii DNA by the use of modifications appropriate to a single stage PCR [7]. The present study investigated the ability of a nested B1 gene PCR $[8,9]$ to identify toxoplasma infection in a routine diagnostic laboratory not solely dedicated to PCR testing, and the stability of experimentally infected amniotic fluids. 


\section{Materials and methods}

\section{Samples}

Amniotic fluids (17 samples) remaining after diagnostic tests were collected anonymously from patients undergoing amniocentesis for investigations other than $T$. gondii infection. Wet preparations were examined microscopically for erythrocyte and other cell (leucocyte, epithelial cell) content. Six 1-ml aliquots of each sample were dispensed in $1.5-\mathrm{ml}$ microcentrifuge tubes.

T. gondii RH strain [10] tachyzoites, freshly collected from the peritoneums of experimentally infected cotton rats, were washed once with isotonic saline and the concentration was determined by phase contrast microscopy with a Neubauer counting chamber. Dilutions containing 16, 32, 80, 160 and 1600 parasites $/ 20 \mu \mathrm{l}$ of saline were prepared. Twenty $\mu \mathrm{l}$ of each dilution were added to a 1-ml aliquot of amniotic fluid, leaving one unseeded control aliquot. Amniotic fluid samples were stored at $4^{\circ} \mathrm{C}$ (four samples) or room temperature (13 samples) for up to 16 days. On days $1,5 \pm 1,8 \pm 1$ and $15 \pm 1$, a 0.25 -ml sample (containing $0,4,8,20,40$ or 400 parasites) was removed from each seeded mixture and centrifuged at $10000^{\circ} \mathrm{g}$ for $5 \mathrm{~min}$. The deposit was washed once with $1 \mathrm{ml}$ of sterile distilled water (SDW) $(10000 \mathrm{~g}$ for $5 \mathrm{~min}$ ) before resuspending in SDW $40 \mu \mathrm{l}$. Half of this suspension was diluted with SDW $20 \mu 1$ and half with buffered proteinase K (Sigma) $20 \mu \mathrm{l}$ (final concentrations: proteinase $\mathrm{K} 200 \mu \mathrm{g} / \mathrm{ml} ; 50 \mathrm{mM}$ Tris- $\mathrm{HCl} ; 1 \mathrm{mM}$ EDTA disodium; Tween $200.5 \%$ ), so that at each time point $2 \times 20-\mu 1$ samples were prepared in SDW and $2 \times 20-\mu 1$ samples in proteinase $\mathrm{K}$, each containing 0 , $1,2,5,10$ or 100 parasites.

\section{Sample extraction}

Amniotic fluid deposits in SDW were boiled for $15 \mathrm{~min}$. Proteinase K-treated samples were incubated at $56^{\circ} \mathrm{C}$ for $2 \mathrm{~h}$, then boiled for $10 \mathrm{~min}$. All were then stored at $-20^{\circ} \mathrm{C}$ until required.

\section{$P C R$}

A nested PCR was performed as described previously $[8,9]$ but with a different source of Taq polymerase, reaction buffer $\left(10 \times\right.$ concentrated) and $\mathrm{MgCl}_{2}$ (all from Advanced Biotechnologies Ltd, Leatherhead, Surrey). Each PCR reaction contained $0.8 \mathrm{u}$ of enzyme, $1 \times$ buffer, $1.5 \mathrm{mM} \mathrm{MgCl}_{2}, 0.2 \mathrm{mM}$ each dATP, dCTP, dGTP and dTTP (Advanced Biotechnologies) and 20 pmols of each primer. Primers S114 and S115 [9] were used in the first round PCR, and primers S331 and P456 [9] at the nested stage. All primers were from Severn Biotech, Kidderminster. Samples $(20 \mu 1)$ were tested in a final reaction volume of $50 \mu \mathrm{l}$ as described previously $[8,9]$. The PCR positive controls were suspensions of 10 and $1 \mathrm{RH}$ tachyzoite $/ 20 \mu \mathrm{l}$ of water prepared just before use from a stock of $10^{4}$ tachyzoites $/ 20 \mu \mathrm{l}$, stored at $4^{\circ} \mathrm{C}$ in saline or water containing sodium azide $0.1 \%$.

Compared to the method described previously $[8,9]$, the number of cycles in the first stage PCR was increased from 30 to 40 cycles of $94^{\circ} \mathrm{C}$ for $1 \mathrm{~min}$, $53^{\circ} \mathrm{C}$ for $1 \mathrm{~min}, 72^{\circ} \mathrm{C}$ for $1 \mathrm{~min}$, followed by a $5-\mathrm{min}$ extension at $72^{\circ} \mathrm{C}$ in a Techne $\mathrm{PHCl}$ or $\mathrm{PHC} 3$ programmable Dri-block (Scotlab, Aberdeen). For the nested PCR, the number of cycles was reduced from 17 to 14 cycles of $94^{\circ} \mathrm{C}$ for $1 \mathrm{~min}, 53^{\circ} \mathrm{C}$ for $30 \mathrm{~s}, 72^{\circ} \mathrm{C}$ for $30 \mathrm{~s}$, followed by a 5 -min extension, performed on a 1 in 80 dilution in SDW of the primary product. This is the routine method used in the laboratory and has been optimised for the reagents currently used to detect reliably one tachyzoite in the positive control in the shortest overall time. A more stringent annealing temperature $\left(60^{\circ} \mathrm{C}\right)$ was also tested in the first round PCR, $1^{\circ} \mathrm{C}$ below the mean $\mathrm{Tm}$ of the primers. Products at both stages were identified on agarose $2.5 \%$ gels containing ethidium bromide $0.7 \mu \mathrm{g} / \mathrm{ml}$ in $89 \mathrm{mM}$ tris, $89 \mathrm{mM}$ borate, $2.5 \mathrm{mM}$ EDTA buffer (TBE) $\mathrm{pH} 8.3$.

\section{Results}

With occasional exceptions (Fig. 1, lane 7) positive results were detectable after the first round PCR, but nested PCR was essential to confirm specificity of first round products and the enhanced band intensity made results easier to interpret. In the figure, a faint band in the target position for the unseeded sample in lane 5 was not confirmed by nested PCR. With samples lysed by boiling for $15 \mathrm{~min}$ in water, the nested PCR with $60^{\circ} \mathrm{C}$ annealing in the first stage detected more of the samples with $\leqslant 2$ parasites compared to PCR with $53^{\circ} \mathrm{C}$ annealing ( 7 versus 3 of 17 ), but the difference was not significant $(p=0.26)$ (Table 1). By this procedure, positive results were obtained for 13 of 17 samples containing $\leqslant 10$ parasites, 7 of 17 of which were also positive when they contained $\leqslant 2$ parasites. These results were not significantly different $(p>0.5)$ from those obtained for samples extracted by the proteinase $\mathrm{K}$ method normally used in the laboratory. Samples seeded with 100 parasites (results not shown) were not tested when the same amniotic fluids gave positive results when seeded with fewer parasites.

Most procedures failed to detect $\leqslant 10$ parasites in the same four amniotic fluids. These were not associated with any one of the five different stocks of toxoplasma parasites that were prepared during the study for seeding amniotic fluids. However, all four samples involved storage of the parasites for one or more days between preparation and seeding; this significantly reduced sensitivity $(p=0.004)$. The amounts of erythrocyte, leucocyte or epithelial cell contamination were not significant factors in PCR sensitivity 




Fig. 1. PCR products (arrowed) after first round (bottom panel; $194 \mathrm{bp}$ ) and nested stages (top panel; $97 \mathrm{bp}$ ) on ethidium bromide stained agarose gel: lanes 1, 14, marker ladder; 2-5, unseeded samples; 6-11, samples seeded with one parasite; 12,13 , positive controls containing one and 10 parasites, respectively.

Table 1. Comparison of PCR results for freshly seeded samples examined by two extraction methods and annealing temperatures

\begin{tabular}{|c|c|c|c|c|}
\hline \multirow{3}{*}{$\begin{array}{l}\text { Number } \\
\text { of parasites } \\
\text { in sample }\end{array}$} & \multicolumn{4}{|c|}{ Number of PCR-positive results after } \\
\hline & \multicolumn{2}{|c|}{ Boiling } & \multicolumn{2}{|c|}{ Proteinase $\mathrm{K}$} \\
\hline & $\begin{array}{l}53^{\circ} \mathrm{C} \\
\quad(\text { an }\end{array}$ & $\begin{array}{l}60^{\circ} \mathrm{C} \\
\text { aling) }\end{array}$ & \multicolumn{2}{|c|}{ (annealing) } \\
\hline First stage $P C R$ & $(\mathrm{n}=17)$ & $(\mathrm{n}=16)^{*}$ & $(\mathrm{n}=15)^{*}$ & $(\mathrm{n}=14)^{*}$ \\
\hline Unseeded & 0 & 2 & 5 & 1 \\
\hline$\leqslant 2$ & 1 & 5 & 6 & 3 \\
\hline$\leqslant 10$ & 11 & 13 & 9 & 12 \\
\hline Nested PCR & $(\mathrm{n}=17)$ & $(\mathrm{n}=17)$ & $(\mathrm{n}=17)$ & $(\mathrm{n}=17)$ \\
\hline Unseeded & 2 & 4 & 3 & 2 \\
\hline$\leqslant 2$ & 3 & 7 & 5 & 4 \\
\hline$\leqslant 10$ & 14 & 13 & 13 & 12 \\
\hline
\end{tabular}

n, number of samples tested.

*The remaining samples were not examined by electrophoresis.

$(\mathrm{p}=0.07)$. There was no evidence of loss of PCR sensitivity, with any extraction or test method, after storage of seeded amniotic fluids for a week or more. If anything there was an apparent marginal improvement. This was found regardless of whether samples were stored at $4^{\circ} \mathrm{C}$ (four samples) or room temperature (13 samples). Six samples were stored for a further week at room temperature without loss of sensitivity.

Combining all the data on unseeded samples, positive nested PCR results were obtained for $14 \%$ of 98 boiled samples and $15 \%$ of 88 proteinase K-extracted samples. A similar proportion were PCR positive after the first stage; $13 \%$ of 94 boiled samples and $20 \%$ of 85 proteinase K-extracted samples. In 16 of the 17 samples, positive results were randomly distributed and not consistently associated with any one amniotic fluid, indicating that they were false positive results. In the seventeenth sample, the fact that there was a concentration of positive results in tests on the unseeded sample which had been stored for a week, and negative results were found in more than half of the seeded samples similarly stored, again suggests contamination of the unseeded sample. These figures compare with only $1.9 \%$ false positive nested PCR results (four positive and one weak positive in 258 tests) in tests carried out on routine PCR-negative samples or controls during the same period. 


\section{Discussion}

The ability of a nested PCR to detect $T$. gondii in amniotic fluids in a routine diagnostic laboratory setting was investigated. There was no advantage in proteinase $\mathrm{K}$ extraction thus the simpler boiled-lysis method would appear to be the method of choice for the preparation of amniotic fluid containing $T$. gondii for PCR. A single-step PCR would be simpler and reduce the risk of false positive results from crosscontamination. Most positive results were detected after the first stage, but they require confirmation and nested PCR with primers specific to the internal sequence of the first-stage product is faster than the alternative method of hybridisation, avoids radioactive or other expensive labelled probes and is technically easier for a routine laboratory. As the methods for counting and diluting tachyzoite suspensions used in the present study probably do not guarantee the presence of precisely one, two, five and 10 parasites in the test samples, results were analysed at two detection thresholds, $\leqslant 2$ parasites and $\leqslant 10$ parasites. Virtually all of the samples in which $\leqslant 10$ parasites were not detected involved samples seeded with stored parasites. It has been observed that parasites stored at concentrations below $30 / 20 \mu \mathrm{l}$ in saline without sodium azide produce negative PCR results, which suggests that parasite lysis or DNA degradation during storage prior to seeding may have influenced these results. In contrast, freshly prepared parasites in amniotic fluid may be less susceptible to lysis or degradation, so that small numbers remain detectable.

The markedly higher false positive rate in the samples tested in this study compared to routine samples tested in the same period reflects different handling conditions. Routine samples, the great majority of which are negative, were prepared and diluted in small numbers in facilities strictly isolated from the positive controls and from the later stages of the PCR. In contrast, the great majority of the experimental samples were, by intention, positive and were handled together with the unseeded negative controls during all stages of the PCR. Consequently the risk of crosscontamination with target was greater. However, the PCR described is suitable for the diagnosis of toxoplasma infection in amniotic fluids where test conditions and cross-contamination risks would be the same as for other routine specimens. As well as PCR stage segregation, recognised precautions [11] are used in this laboratory, including the use of sterile reagents and plastics, frequent glove changes, opening and closing of tubes in turn, pipettes dedicated to each PCR stage, UV irradiation between experiments, and single use of tips. In the nested PCR described here, it is not possible to use the modified phage internal positive control used in the single stage PCR [7] but the toxoplasma positive control is not handled until all test samples are prepared and placed in the thermal cycler, to minimise cross-contamination.
The expected parasite concentration in clinical samples is not known but other workers [7] detected fetal infection by testing one-fifth of a $1.5-\mathrm{ml}$ sample in all patients tested (37) except one which was tested early after maternal infection. In the present study, $0.25-\mathrm{ml}$ volumes of amniotic fluid containing 4-40 parasites were sampled but larger volumes could easily be concentrated at the initial centrifugation stage. The resulting increased concentration of human cells, especially erythrocytes, might inhibit the PCR $[9,12]$, but there was no evidence that these interfered significantly in this study. The lower intensity of some bands relative to the positive controls may suggest some degree of inhibition by these samples. Washing amniotic fluid deposits with water, as described, reduces the inhibition by haemoglobin from erythrocytes [9] and routine diagnostic samples are always checked for inhibition by spiking a duplicate sample with one parasite from the positive control stock solution.

Tachyzoites are the parasite stage most likely to be present in infected amniotic fluids, perhaps within infected cells [13], and the most vulnerable to destruction [14]. As they remained detectable in samples stored for up to 2 weeks at room temperature, posting samples to a reference laboratory should not impair diagnosis and would allow centralisation of resources and expertise. Diagnosis of maternal toxoplasmosis may be slow in countries like the UK which have no systematic screening programmes [1]. Therefore, it is important that rapid fetal diagnostic methods like PCR are available in laboratories that have expertise in detecting toxoplasma, although the lower incidence of the disease in countries such as the UK compared to, for example, France means that facilities dedicated to toxoplasma PCR are not necessary.

This work was supported by a grant from the Scottish Home and Health Department (reference K/MRS/50/C1828). We are very grateful for the superb co-operation of Drs M. Hulse, D. A. R. Lees, B. Milne and M. W. MacLean, without whose help this study would not have been possible. We thank Mr J. McGhee for the illustration and Miss Lorna Wycherley for invaluable secretarial assistance.

\section{References}

1. Chatterton JMW. Pregnancy. In: Ho-Yen DO, Joss AWL (eds) Human toxoplasmosis. Oxford, Oxford University Press. 1992: $144-183$.

2. Daffos F, Forestier F, Capella-Pavlovsky $\mathrm{M}$ et al. Prenatal management of 746 pregnancies at risk for congenital toxoplasmosis. $N$ Engl $J$ Med 1988; 318: $271-275$.

3. Desmonts G, Daffos F, Forestier F, Capella-Pavlovsky M, Thulliez P, Chartier M. Prenatal diagnosis of congenital toxoplasmosis. Lancet 1985; 1: 500-504.

4. Hohlfeld P, Daffos F, Thulliez P et al. Fetal toxoplasmosis: outcome of pregnancy and infant follow-up after in utero treatment. J Pediatr 1989; 115: 765-769.

5. Grose C, Itani O, Weiner CP. Prenatal diagnosis of fetal infection: advances from amniocentesis to cordocentesis congenital toxoplasmosis, rubella, cytomegalovirus, varicella virus, parvovirus and human immunodeficiency virus. Pediatr Infect Dis J 1989; 8: 459-468. 
6. Pratlong F, Boulot $\mathrm{P}$, Issert $\mathrm{E}$ et al. Fetal diagnosis of toxoplasmosis in 190 women infected during pregnancy. Prenat Diagn 1994; 14: 191-198.

7. Hohlfeld P, Daffos F, Costa J-M, Thulliez P, Forestier F, Vidaud M. Prenatal diagnosis of congenital toxoplasmosis with a polymerase-chain-reaction test on amniotic fluid. $N \mathrm{Engl} J$ Med 1994; 33: 695-699.

8. Ho-Yen DO, Joss AWL, Balfour AH, Smyth ETM, Baird D, Chatterton JMW. Use of the polymerase chain reaction to detect Toxoplasma gondii in human blood samples. J Clin Pathol 1992; 45: 910-913.

9. Joss AWL, Chatterton JMW, Evans R, Ho-Yen DO. Toxoplasma polymerase chain reaction on experimental blood samples. $J$ Med Microbiol 1993; 38: 38-43.
10. Sabin AB. Toxoplasmic encephalitis in children. JAMA 1941; 116: $801-807$.

11. Kwok S, Higuchi R. Avoiding false positives with PCR. Nature 1989; 339: 237-238. (Erratum: Nature 1989; 339: 490).

12. Joss AWL, Ho-Yen DO. PCR in the detection of parasitic protozoa, in particular Toxoplasma gondii. In: Latchman DS (ed) PCR applications in pathology. Principles and practice. Oxford, Oxford University Press. 1995: 108-128.

13. Remington JS, Desmonts G. Toxoplasmosis. In: Remington JS, Klein JO (eds) Infectious diseases of the fetus and newborn infant, 3rd edn. Philadelphia, WB Saunders Co. 1990: 89-195.

14. Evans R. Life cycle and animal infection. In: Ho-Yen DO, Joss AWL (eds) Human toxoplasmosis. Oxford, Oxford University Press. 1992: 26-55. 